\title{
SAVITZKY-GOLAY METHOD FOR THE EVALUATION OF DECELERATION OF THE FIRCTION LIFT
}

\author{
Paweł Lonkwic ${ }^{1}$, Kamil Szydło², Szymon Molski ${ }^{3}$ \\ 1 The State School of Higher Education in Chełm, Depułtyczne Królewskie, Poland, e-mail: plonkwic@gmail.com \\ 2 Lublin University of Technology, Faculty of Mechanical Engineering, Department of Automotive Vehicles, \\ Lublin, Poland \\ 3 AGH University of Science and Technology, Faculty of Mechanical Engineering and Robotics Department of \\ Rope Transport, Kraków, Poland
}

Received: 2016.12 .15

Accepted: 2017.02.01

Published: 2017.03.01

\begin{abstract}
Due to self-acting variability of operating conditions during the work of lifting devices, it is fundamental for the gears to stop the cabin at any clearance height. The operating conditions are changed by dust contamination influencing a proper braking process of the gear. This article presents the independent tests results. The impact of progressive gear geometry on the braking distance both in variable operating conditions and variable loading is analyzed. The tests were conducted for the gear applied in short distance transportation devices. Changing operating conditions were obtained by using various lubricating agents. The following five types of the gears were used for the tests: ASG100, PP16, PR2000, KB160. CHP 2000 gear was tested as a new solution. The tests were conducted using a free fall method. The test results obtained from an experiment were approximated by using Savitzky-Golay method.
\end{abstract}

Keywords: safety gears, reliability, traction lift, progressive gears, Savitzky-Golay method.

\section{INTRODUCTION}

The elevator cabin and the gears move along the two guides inside a shaft. The guides are located opposite one another. The elevator operating characteristics determine if the guide surface, along which the gears move, can be greased or not. The elevator operating characteristics depend on the type of guide shoes installed in the elevator. The sliding or the roller guide shoes can be used. For the elevator with the roller guide shoes installed the guides are not greased. For the elevator with the sliding guide shoes the guides require grease application. Contamination is frequent when the elevator works. Dust settles on surface of the guides. Not only does it disturb a proper elevator operation but also it can impact an emergency braking process negatively. The process can be extended leading to the increase of braking process delay value. This research study tries to find the answer to the following questions: How does the contamination on the guide surface influence the emergency braking process? Can the results be helpful in the preparation of potential expert applications to monitor the lifting device operation in the applicable working range by using available tools such as filters.

While analyzing the world literature and the aspects regarding brake systems applied in the friction lifts, it has been noticed that the available information is not sufficient. In the publications No. 2, 4, 9 the authors describe Finite Element Method (FEM). It is used to assess the stiffness and the construction resistance of the cabin frames and the gears in different types of the lifts. Finite Element Method gives a chance to optimize the construc- 
tion of a carrying frame. Thanks to this method the construction mass can be reduced without losing the stiffness. It also helps to identify in the system the areas which are the most loaded and vulnerable to damage. In the publication No. 5 the authors used FEM to determine the value of stresses and displacements of the brake system in the hydraulic lift. The authors compared the results obtained from a numerical analysis with the results of an experiment. According to the authors, the results obtained from the experiment are compatible with the results obtained from a simulation. In the publication No. 10 the authors focus on the aspects connected with the application of neural networks. The neural networks are used to analyze the vibrations of the working elevator. The vibrations are generated by variable mass of transported loading. The neural networks are used to evaluate the symptoms of vibrations. Thanks to the symptoms it is possible to detect damage of the lift subassembly. The damage can lead to failure of the entire device. Reduction method to assess the dynamics of the working elevator is analyzed by the authors in the publication No. 7. In the presented analyses the model of a lift cabin was reduced to the flat system with one, vertical level of leeway. By using the reduction methodology the authors described a specific mechanism of a cargo lift. This description was prepared in a mathematical way. Additionally, the authors analyzed which parameters of the lift operation influence the accelerations characteristics of the lift system. The aspects referring to dynamics of the elevator brake system, the analysis of used materials and the gears themselves are also touched in the research studies No. 3, 6 and 8. In the above mentioned scientific papers the authors focus their attention on the analysis of braking system. Moreover, they compared the construction and operation of the gears made by European manufacturers with a newly developed solution of CHP 2000 type progressive gears optimized by Finite Element Analysis. The publication No. 11 presents the aspects referring to the impact of mass of the cabin power supply wires and the carrying ropes on the elevators operated in the buildings above 40 stories tall. In this kind of lifts, a significant height of lifting creates a need to use the leveling belts. The belts compensate a changing weight of carrying ropes and power supply wires. In consequence some other subassemblies of the elevator are not excessively loaded. The authors described the leveling belt behavior in a model way. Also the belt impact on the linear model of the lift operation is presented. Additionally, they analyzed the impact of horizontal displacements of the leveling belt on frequencies of the system vibrations.

Analyzing the world literature it can be stated that there are no clear research studies with simulation tests results for the brake systems in variable operating conditions and the impact of those conditions on the braking distance. The braking distance is a key parameter to evaluate the compliance of a given progressive gear. Consequently, it is justifiable to continue further research tests on the impact of changing loading and variable operating conditions on the braking process of progressive gears.

\section{EXPERIMENTAL TESTS}

The braking process was tested for non-lubricated system of the guides. Two types of lubricants and their mixtures were used for the tests. The above mentioned lubricants are commonly used as applications reducing the friction in lifting machines. The code identification of various conditions of the guides prepared for the tests is presented below:

- Dry operation - without lubricant,

- Mineral oil - the guides lubricated with RENOLIN B20 oil,

- Solid grease - the guides lubricated with ŁT43 grease as per ISO 6743-9 RENOLIN B20,

- $\mathrm{O} 50 \mathrm{~B}$ - the guides lubricated with the mixture of RENOLIN B20 oil and quartz sand in 50/50 proportion,

- $\mathrm{S} 50 \mathrm{~B}$ - the guides lubricated with the mixture of ŁT-43 grease and quartz sand in 50/50 proportion,

Quartz sand contained in the mixtures with lubricants was to imitate the real contamination of the guides during their regular operation. Four types of the gears made by European manufacturers and the fifth self-construction gear of CHP2000 type were selected for the tests. Each type of the gear was loaded with a typical loading in a range from 400 to $1200 \mathrm{~kg}$ and tested in five different types of operating conditions. In consequence 25 measurements were received for each type of the gear.

\section{The gears characteristic}

Progressive characteristic of braking process is the main feature distinguished for the progressive gears. In consequence, the energy of speed- 


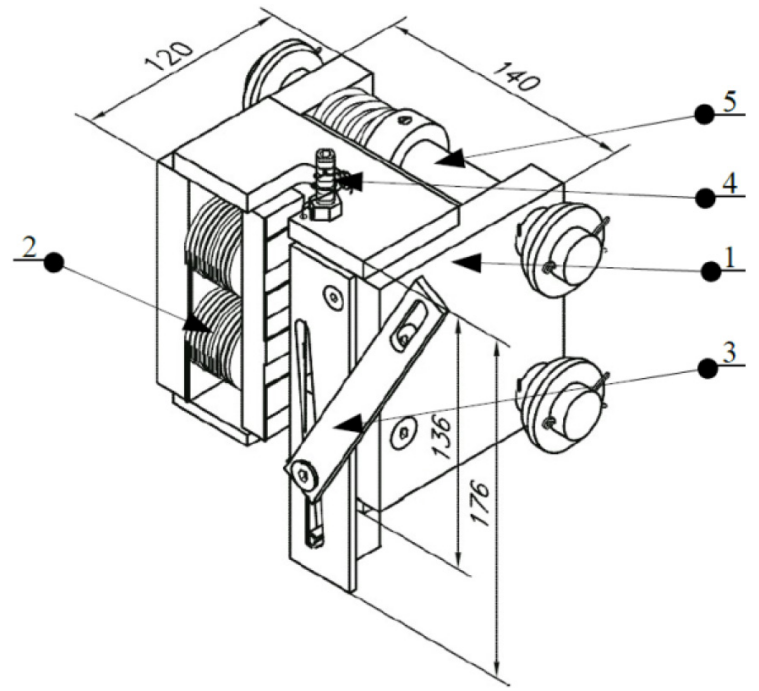

Fig. 1. Schematic drawing of progressive safety gears - KB160 type: 1 - body, 2 - Belleville springs, 3 lever, 4 - screw to limit a wedge stroke, 5 - the gear mounting mechanism $[7,15]$

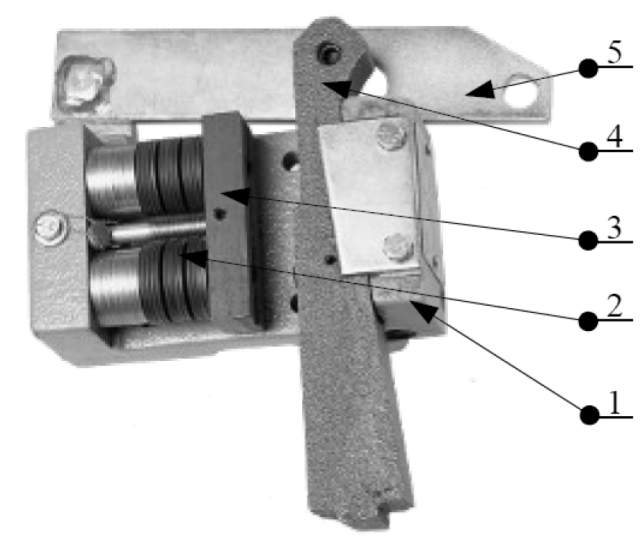

Fig. 2. Schematic drawing of progressive safety gears - ASG100 type: 1 - body, 2 - blocking roller, 3 clamping spring, 4 - wegde, 5 - lever [7, 17]

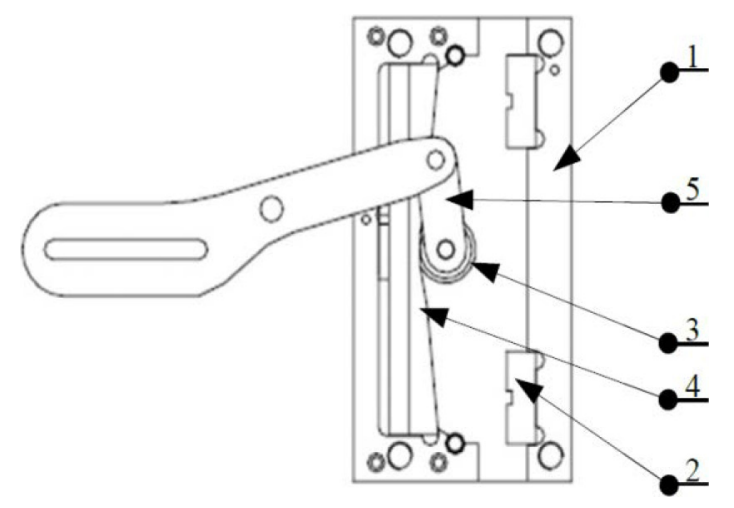

Fig. 3. Schematic drawing of progressive safety gears - PR2000UD type: 1 - body, 2 - braking plate, 3 clamping roller, 4 - wedge, 5 - lever $[7,16]$

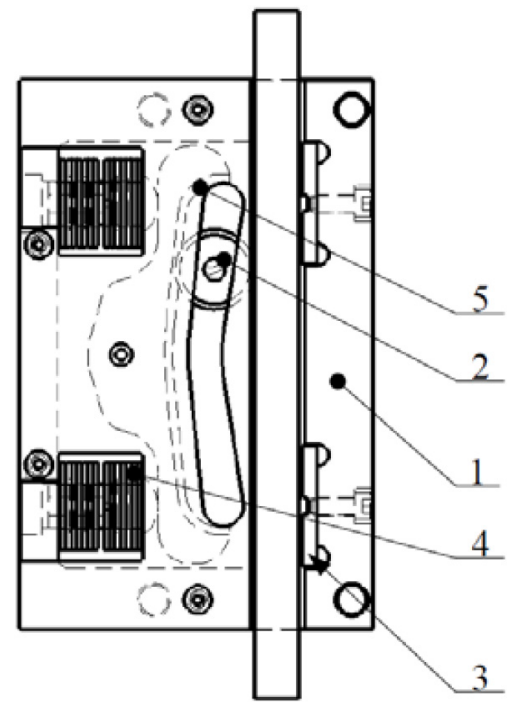

Fig. 4. Schematic drawing of progressive safety gears - CHP2000 type: 1 - body, 2 - braking roller, 3 braking plate, 4 - Belleville springs, 5 - wedge [7]

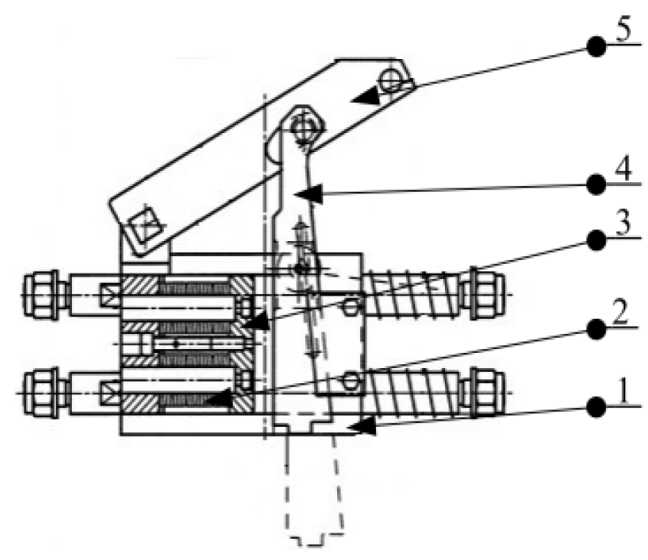

Fig. 5. Schematic drawing of progressive safety gears - PP16 type: 1 - body, 2 - Belleville springs, 3 braking plate, 4 -wedge, 5 - lever $[7,16]$

ing mass is reduced along a certain distance. That distance not only depends on the gear construction, but also on the conditions in which the braking process takes place. The tested gears are presented in Figures 1-5.

Free fall of the friction lift system was simulated. It was done by cutting off the carrying ties. The elevator support frame equipped with the gears was installed to those ties. A special test bench was built for the test. It is presented in Figure 6.

The guides No. 7 were installed in the test bench construction. The frame No. 6, equipped with the gears No. 1, was moving along the guides. The frame and the gears were joined with control system. The system was controlling the 


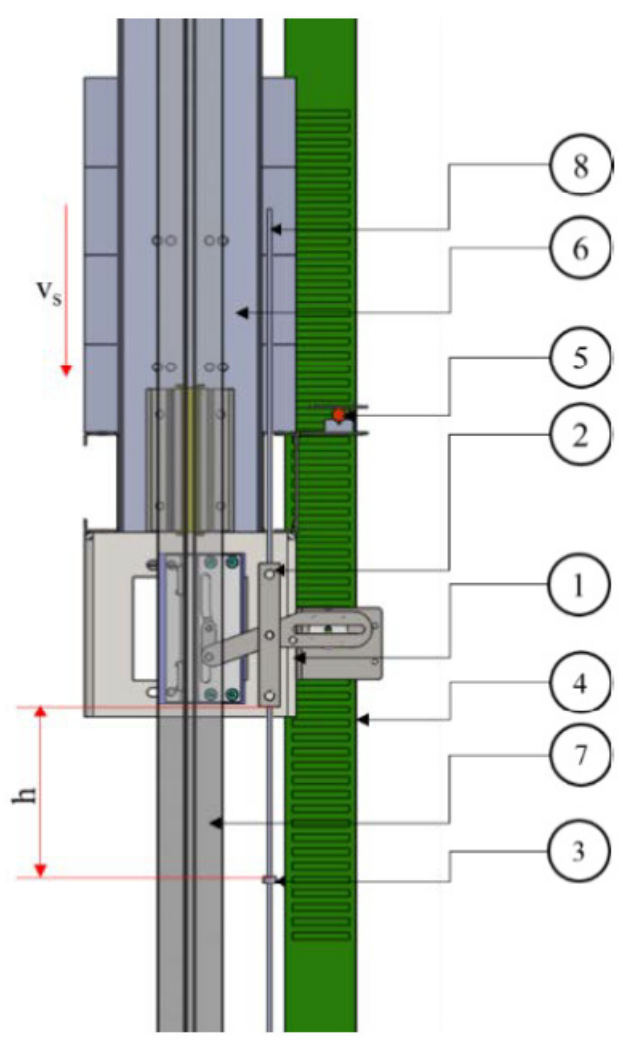

Fig. 6. The test bench scheme

free fall speed No. 8. The system was to initiate the braking process after exceeding the nominal speed by $0.3 \mathrm{~m} / \mathrm{s}$. The measurement of braking parameters was recorded by MMA7341LC type accelerometer made by Pololu 5 company. The device was joined with PC class computer. Both ,aop” delay parameter and ,„” parameter of the free fall distance were recorded. The latter was recorded by CFR-22 type optical sensor made by Sensor company. It was the sensor with $10 \mathrm{~mm}$ graduations and it was placed on the bar No. 4. Once the free fall was started, the lever of the gear No. 2 hit the clamp of the rope No. 3. In consequence, the braking process was initiated. The height, at which the frame system should have been lifted to activate the gears when the speed was exceeded by $0.3 \mathrm{~m} / \mathrm{s}$ versus the nominal speed, was determined by empirical dependencies of potential and kinetic energy using the formula (1).

$$
h=\frac{v_{1}^{2}}{2 \cdot g}+0,1+0,03
$$

where: 0.03 - the excessive clearance coefficient in the brake system (-),

0.1 - the delay coefficient of the gears activation (-),

$\mathrm{v} 1$ - the speed of the gears release, 1.25 $(\mathrm{m} / \mathrm{s})$ value accepted for tests, $\mathrm{g}$ - the acceleration of gravity $\left(\mathrm{m} / \mathrm{s}^{2}\right)$.

The free fall height $h$ was described by an empirical dependence No. (1) using the law of conservation of energy. The free fall value of $250 \mathrm{~mm}$ was determined by using the speed at which the

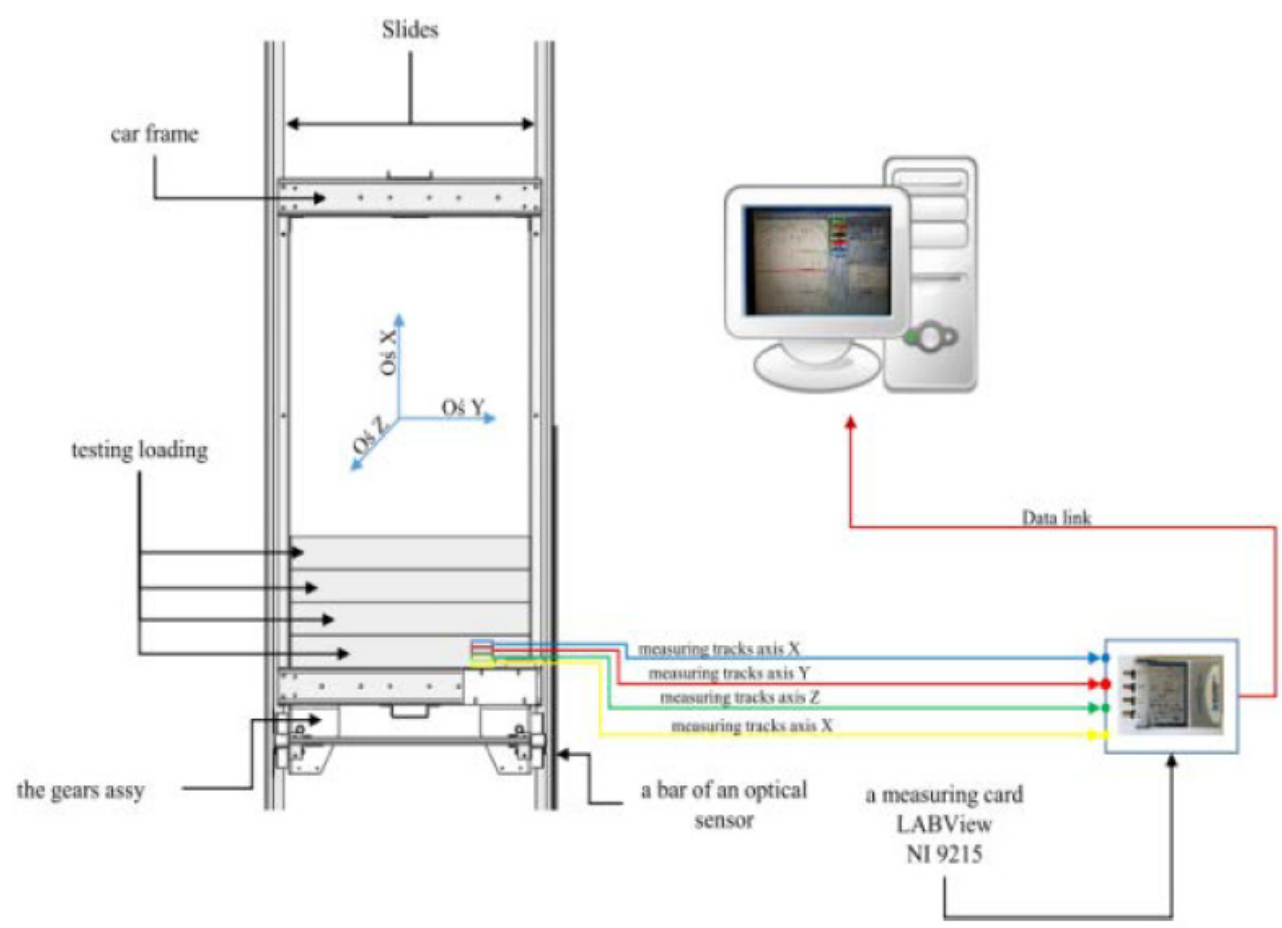

Fig. 7. The test bench scheme 
brake system was activated $v_{1}$, the acceleration of gravity value $g$, the constant 0.1 responsible for the gears start up delay and the constant 0.03 . The constants included in dependence No. (1) are defined by the standard 14. Scheme of the test bench is presented in Figure 7. Measuring equipment and dedicated software, developed especially for the tests, were used for the measurements of accelerations and braking distance. All four measuring tracks were connected with LABVIEW 9215 measuring card. The card was joined with PC class computer to record collected data.

\section{SAVITZKY-GOLAY (S-G) METHOD}

The received courses of braking delay were analyzed by using Savitzky-Golay filter. The method consists of the application of local polynomial regression to receive a smooth value of a specific point in time series. The calculations for every single point are done irrespective of all remaining points. Particularly, the results obtained by filtering are characterized by better imitation of maxima and minima of the output data. It is in opposition to the procedures of classical data smoothing (e.g. a moving average which can be described as a special example of a simple Savitzky-Golay filter) 12. Savitzky-Golay method is also used by the authors in other fields of operation such as chemical industry 1,13 .

The values of successively calculated points are determined typically as a certain linear combination of a specific point value and surrounding points values. Dependency No. (2) was used for the calculations.

$$
g_{i}=\sum_{n=-n_{L}}^{n_{R}} c_{n} f_{i+1}
$$

For S-G filter the values of consecutive coefficients $\mathrm{c}_{\mathrm{n}}$ are calculated by using a mathematical dependency No. (3):

$$
c_{n}=\left(\left(A_{T} A\right)^{-1}\left(A^{T} e_{n}\right)\right)_{0}
$$

where: $A i j=i$;

$$
\mathrm{i}=\mathrm{nL}, \ldots, \mathrm{nR}
$$$$
\mathrm{j}=0, \ldots, \mathrm{M}
$$

Characteristics of the gears braking process were filtered by using filtering methods such as: adjacent-averaging, Savitzky-Golay, Percentile Filter and FFT Filter. Generally, the filters were to smooth the peak values to identify differences between received values. The pre-analysis of received characteristics proved that the filter using Savitzky-Golay function reflected the peak values to the greatest extent. There was no need to create a complicated filtering system. A second degree polynomial was used. The received characteristics of the elevators braking delay were approximated within 50 points. The 50 points reflected a size of a measuring frame.

\section{RESULTS}

The number of collected data was huge. In consequence, it was decided to collate two the most similar design models of the gears in this scientific paper. The loadings 800, 1000 and 1200 $\mathrm{kg}$ were taken for the test. With those loadings

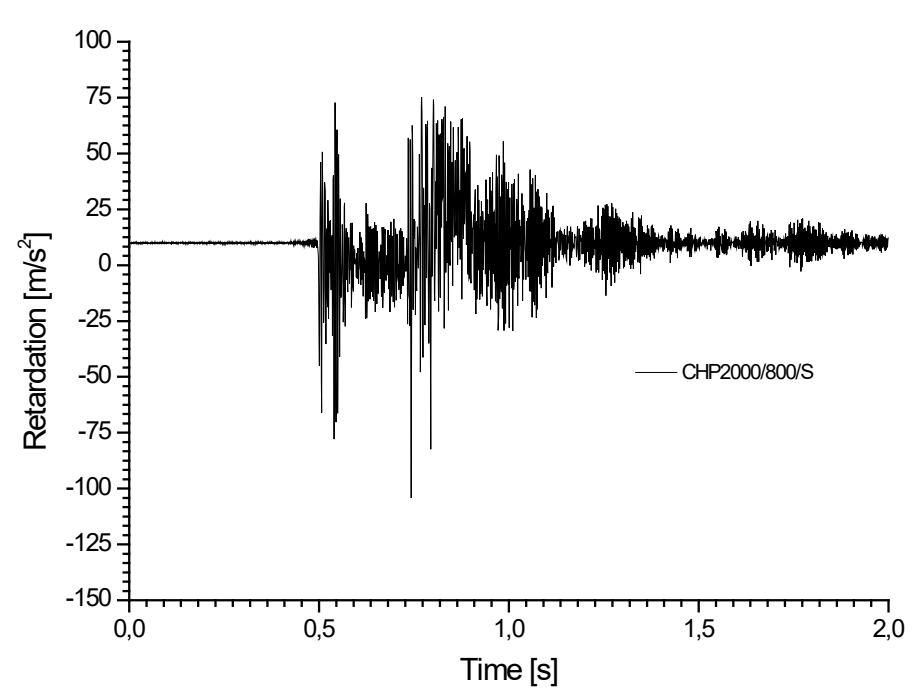

Fig. 8. Characteristic of delay for CHP2000 gear with $800 \mathrm{~kg}$ loading in dry operation 


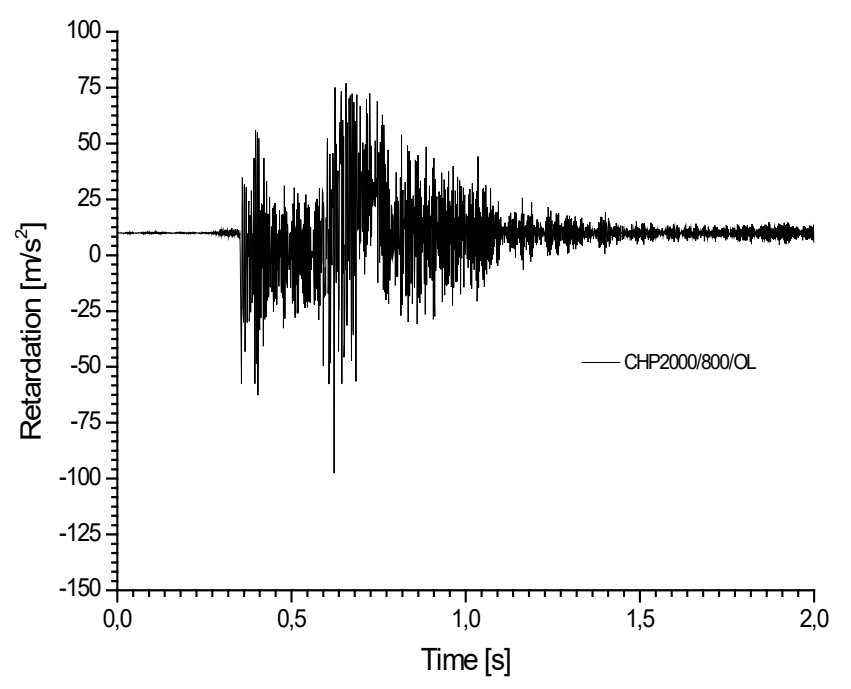

Fig. 9. Characteristic of delay for CHP2000 gear with $800 \mathrm{~kg}$ loading with oil applied

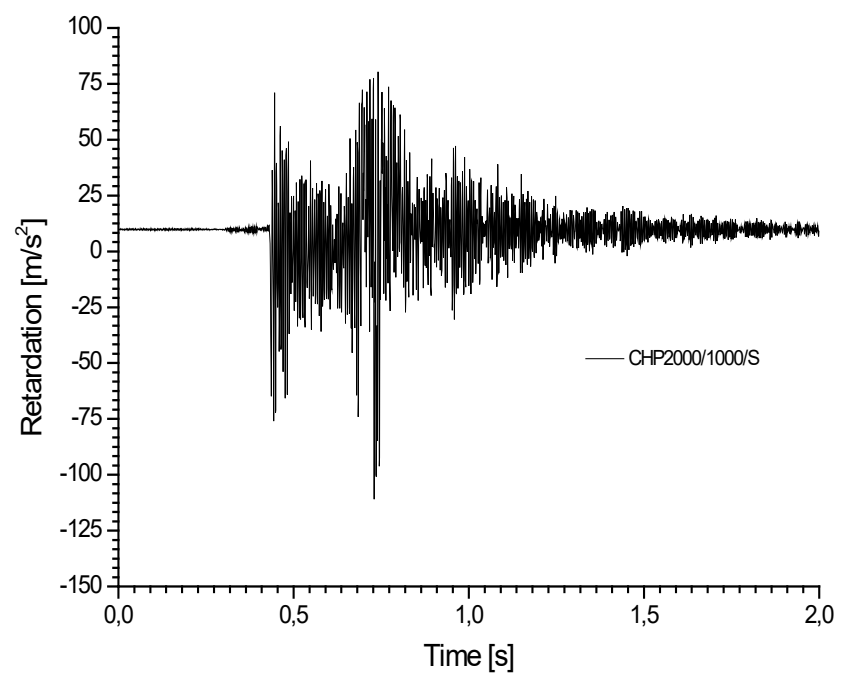

Fig. 10. Characteristic of delay for CHP2000 gear with $1000 \mathrm{~kg}$ loading in dry operation

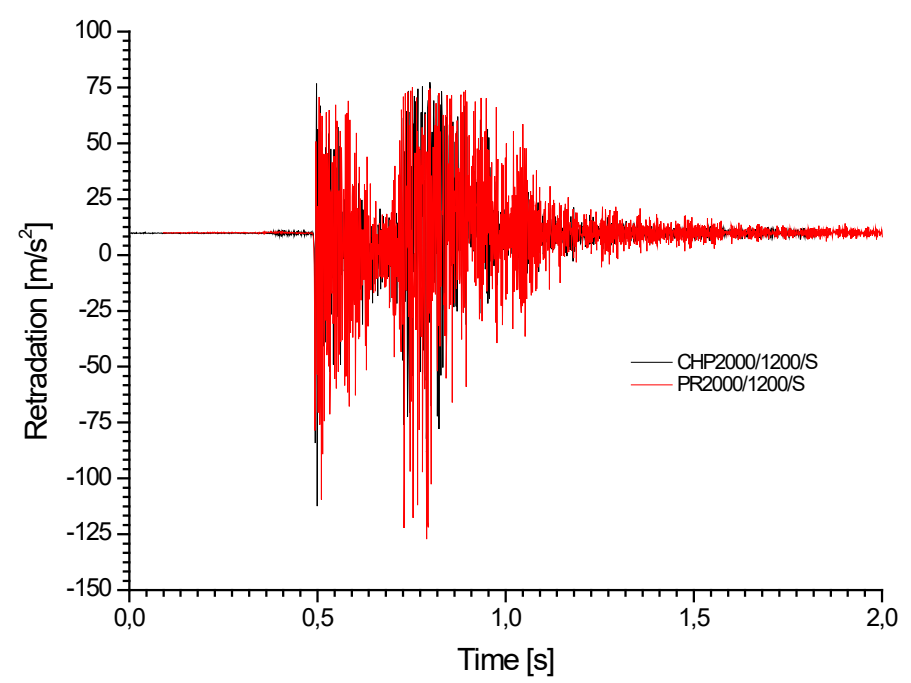

Fig. 11. Characteristic of delay for CHP2000 gear with $1200 \mathrm{~kg}$ loading in dry operation 
the variable conditions allow the authors to notice some differences.

Examples of delay characteristics prepared for the system equipped with CHP2000 gears are presented in Figures 8-10. These are characteristics based on data collected from a measuring system presented in Figure 6 and 7. The chapter does not present all received characteristics. There are only some examples of characteristics for CHP2000 and PR2000UD gears.

The comparison of tests results for delay of the systems braking process is presented in Figures 11-14.

All characteristics presented in Figures 8-10 are evidently buzzed. In consequence, the analysis of braking distance, based on characteristics, is more difficult and involves huge error. Analyzing the braking distance in various operating conditions by putting the received characteristics on one graph, presented in Figure 12, the read-out and comparison of collected results become impossible.

S-G method, as a tool to approximate the characteristics received from the experiment, is presented in Figures 13-14. Smoothing by the second degree polynomial and by using S-G filter gave the most satisfying results for the characteristics approximation after comparison with the higher degree polynomials.

The application of S-G filter to approximate the characteristics received from the experiment is presented in Figures 13-14. The characteristics of braking process for PR2000 type gear in different operating conditions are illustrated in

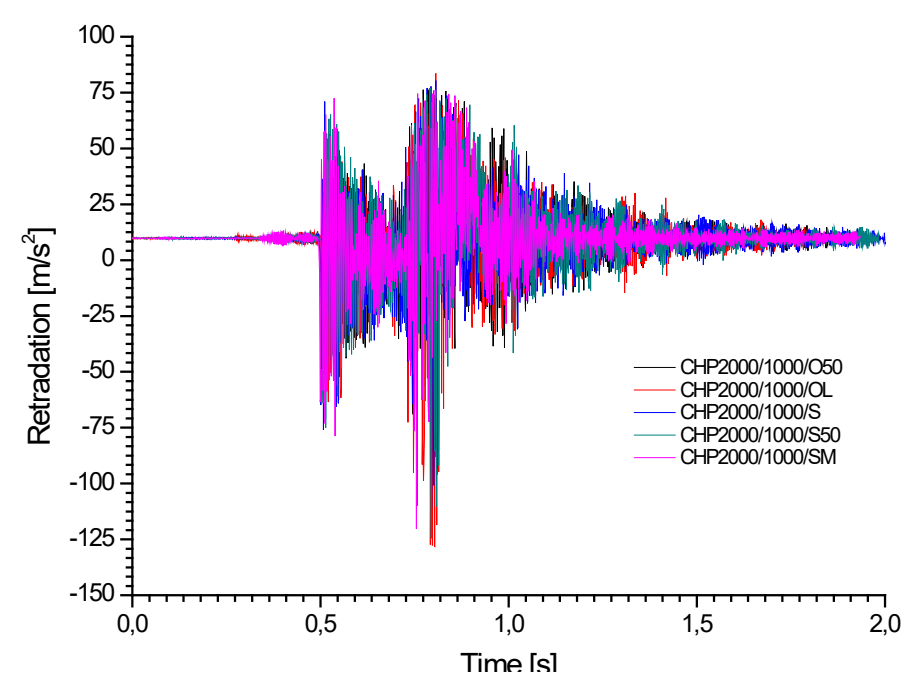

Fig. 12. Characteristic of delay for CHP2000 gear with $1000 \mathrm{~kg}$ loading in five types of operating conditions

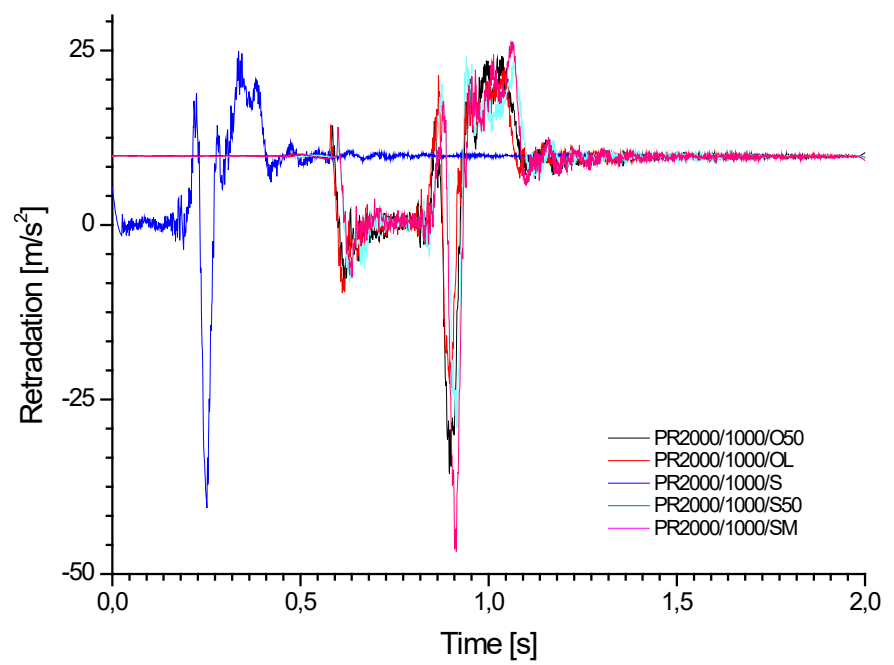

Fig. 13. Characteristics of PR2000 type gears smoothed by S-G filter with $1000 \mathrm{~kg}$ loading in all operating conditions 


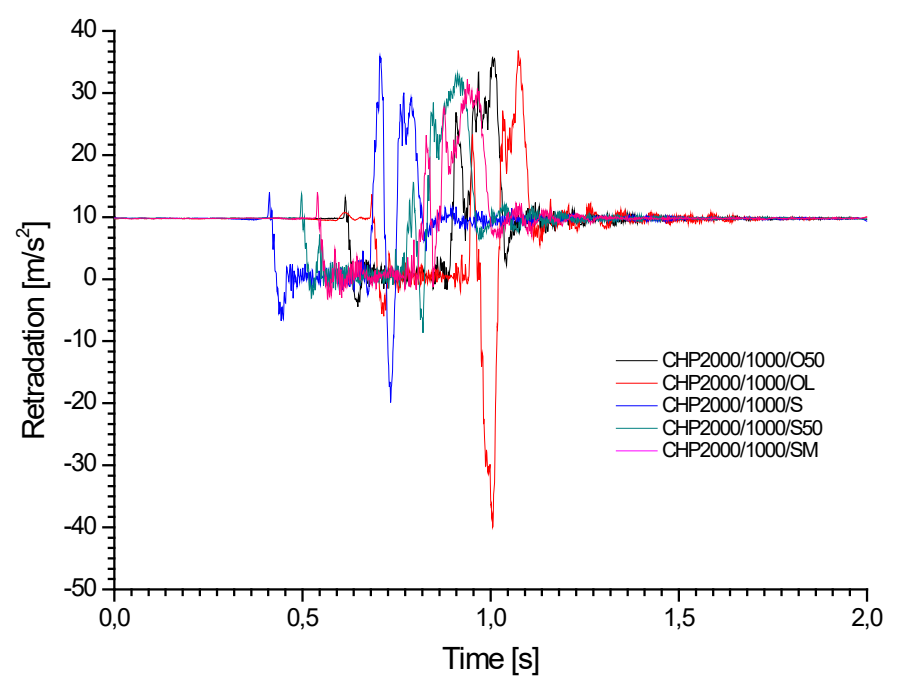

Fig. 14. Characteristics of CHP2000 type gears smoothed by S-G filter with $1000 \mathrm{~kg}$ loading in all operating conditions
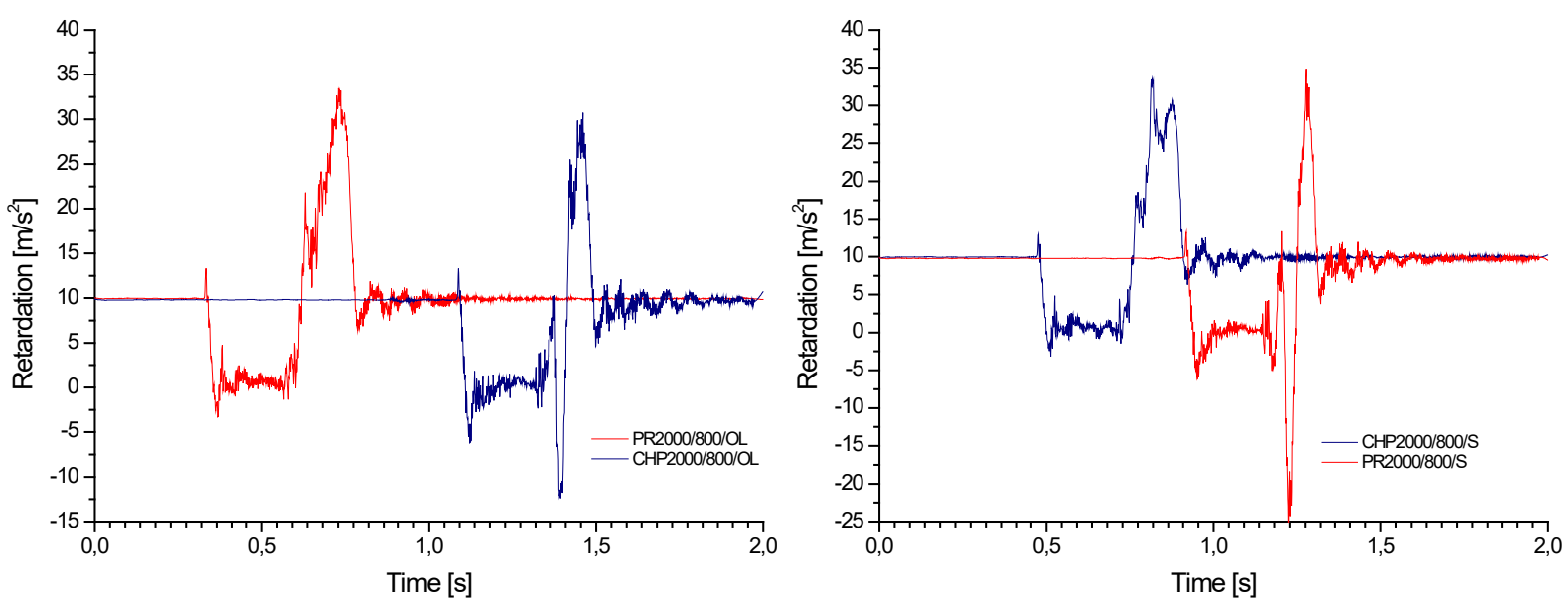

Fig. 15. Characteristics of CHP2000 and PR2000 gears smoothed with S-G filter. The left diagram reflects working conditions with mineral oil and $800 \mathrm{~kg}$ loading. The right diagram reflects dry working conditions and $800 \mathrm{~kg}$ loading

Figure 14. The characteristic of braking process with a mixture made with grease and quartz sand (blue line) was moved aside on purpose to demonstrate a difference between a peak value and the remaining characteristics. While analyzing the peak values presented in Figure 14, a difference can be noticed within the limits of delay values. It is represented by the tested gear working in different operating conditions. The biggest value of delay $47 \mathrm{~m} / \mathrm{s}^{2}$ was recorded in the test of the gears start up in the conditions with mineral oil applied. The values of delays in dry conditions and mixtures with quartz sand are lower and they are in a range from 25 to $30 \mathrm{~m} / \mathrm{s}^{2}$. Similar conclusions are drawn when a diagram presented in Figure 13 for $\mathrm{CH} 2000$ gears is analyzed.
The same as in the previous diagram, the highest value of $40 \mathrm{~m} / \mathrm{s}^{2}$ was recorded in the test with mineral oil used (red line). The remaining values of delay deviate from the test where the oil was used. They are maintained in a range from 10 to $20 \mathrm{~m} / \mathrm{s}^{2}$. Figure 15 presents the diagrams with the filter used and the loading in a range of $8000 \mathrm{~N}$ and mineral oil applied for both analyzed gears.

Indirect value of $8000 \mathrm{~N}$ loading was validated with the applicable filter in two different working conditions: with mineral oil and dry operation. The indirect loading validation proves that it is possible to use S-G filter to analyze the values of delays. In validated example, the values of delay for PR2000 gear are equal to $35 \mathrm{~m} /$ $\mathrm{s}^{2}$ and for CHP2000 gear they reach the value 
of $30 \mathrm{~m} / \mathrm{s}^{2}$. The difference between the values is caused by the gears kinematics. Also, the lower the value of delay for CHP2000 gear is, the higher the comfort of travelling for potential passengers is ensured. It refers to the situation of rapid braking. For PR2000 gear the above described scenario does not apply. Similar dependencies between the values were obtained for dry working conditions. The delay value for CHP2000 gear is lower than the one for PR2000 gear by $2.5 \mathrm{~m} / \mathrm{s}^{2}$.

\section{CONCLUSIONS}

The tests were performed in laboratory conditions on the test bench to diagnose the elevators braking systems by using the free fall method. The received characteristics of the elevator braking process delay were approximated with S-G filter in the scope of 50 points reflecting the measuring frame size. It was detected that the applied parameters of filter reflect the real behaviour of tested systems in operating conditions. Moreover, it was stated that it is possible to use S-G filter with the parameters described in Chapter Savitzky-Golay (S-G) Method to analyze and validate the indirect values of loadings. The peak values of respective characteristics, including smoothing, can be used to evaluate the wear and tear of such elements as a roller or the gear braking plate. The lower the peak value of received delay is, the bigger the wear and tear of the gear braking elements takes place. The read-out values can be used as the input data for an expert system. The system can be used to analyze the obtained signals.

S-G filter gave very good results of approximation. Much better projection of maxima and minima was received thanks to that filter in comparison with classical methods.

With reference to the above, further scientific studies should be continued on the impact of variable operating conditions and variable loading on the elevator braking process delay in relation to durability of braking elements.

\section{REFERENCES}

1. Bromba M.U.A., Ziegler H. 1981. Application hints for Savitzky-Golay smoothing filters. Analytical Chemistry, 53 (11), 1583-1586.
2. Feng L., Bao Y., Zhou X., Wang Y. 2012. High Speed Elevator Car Frame's Finite Elements Analysis. Advanced Materials Research, 510, 298-303.

3. Filas J., Mudro M. 2012. The dynamic equation of motion of driving mechanism of a freight elevator", Procedia Engineering, 48, 149-152.

4. Jong de J., 2004. Understanding the natural behavior of elevator safety gears and their triggering. The International Congress on Vertical transportation technologies. Istambul, Turkey.

5. Kayaoglu E., Salman O., Candas A. 2011. Study on Stress and Deformation of an Elevator Safety Gear Brake Block Using Experimental and FEA Methods. Advanced Materials Research, 308-310, 1513-1518.

6. Lonkwic P, Różyło P, Dębski H. 2015. Numerical and experimental analysis of the progressive gear body with the use of finite-element method. Maintenance and Reliability, 17(4): 542-548, http:// dx.doi.org/10.17531/ein.2015.4.9.

7. Lonkwic P. 2015. Influence of friction drive lift gears construction on the length of braking distance", Chinese Journal of Mechanical Engineering, 28(2), 363-368.

8. Lonkwic P., Molski Sz., Szydło K. 2016. The impact of progressive gear geometry on the breaking distance length under changeable operating conditions. Advances in Science and Technology Research Journal, 10(29), 161-167.

9. Onur Y.A., Imrak C.E. 2012. Reliability analysis of elevator car frame using analytical and finite element methods. Building Services Engineering Research \& Technology, 33(3), 293-305.

10. Taplak H., Erkaya S., Yildirim S., Uzmay I. 2014. The Use of Neural Network Predictors for Analyzing the Elevator Vibrations. Mechanical Engineering, 39, 1157-1170.

11. Zhu W.D., Ren H., A linear model of stationary elevator traveling and compensation cables. Journal of Sound and Vibration, 332, 3086-3097.

12. Stefaniuk M., Wojdyła M., Danek T. 2008. Wybrane aspekty przetwarzania danych magnetotellurycznych z obszaru Karpat. Geologia, 34(2), 209-230 (in Polish).

13. Vivo-Truyols G., Schoenmakers P.J. 2006. Automatic selection of optimal Savitzky-Golay smoothing. Analytical Chemistry, 78(13), 4598-4608.

14. Polish Standard PN EN 81.1+A3. Safety Regulations Concerning the Structure and Installation of Lifts, Part I. Electric Lifts.

15. www.wittur.com

16. www.dynatech-elevation.com/

17. www.montanarigiulio.com 